\title{
Descriptive study of 896 Oral squamous cell carcinomas from the only University based Oral Pathology Diagnostic Service in Sri Lanka
}

Primali Rukmal Jayasooriya ${ }^{1}$, Thushara Nilmini Pitakotuwage ${ }^{1}$, Balapuwaduge Ranjit Rigorbert Nihal Mendis² and Tommaso Lombardi ${ }^{2 *}$

\begin{abstract}
Background: The main objective of this study was to describe selected clinico-pathological characteristics of Oral Squamous Cell Carcinoma (OSCC) in Sri-Lanka.

Materials \& methods: The study sample comprised of eight hundred and ninety six biopsies diagnosed as OSCC. The clinical and histopathological features were analyzed using the Chi-square test.

Results: Of the 896 biopsies, 801 were primary OSCCs, while 95 were recurrent OSCCs. Majority of the patients (78 \%) were in the $5^{\text {th }}$ to $7^{\text {th }}$ decades of life and showed a male predilection. The buccal mucosa was the commonest site of primary OSCC comprising of $43 \%$ of the sample. Of the primary OSCCs, with known TNM stage, $86 \%$ were in stage $3 \& 4$ and majority (59 \%) of stage 4 tumours showed tumour at one or more excision margins. Of the recurrent OSCC, $46 \%$ developed their recurrences within one year of the excision of the primary tumour.
\end{abstract}

Conclusion: In Sri-Lanka, OSCC is a major problem. Only half the patients had completely excised tumours (with clearance of $>5 \mathrm{~mm}$ at all excision margins) at operation, and recurrences appeared early. This data should be considered in the future management policy of OSCC in Sri-Lanka.

Keywords: Oral squamous cell carcinoma, Metastasis, Neck dissection

\section{Background}

According to the Sri Lankan cancer incidence data for year 2005, compiled by the National Cancer Control Programme, cancer of the lip, oral cavity and pharynx was the commonest cancer occurring in males with a crude rate of 12.7 per $1,00,000$ population. On the other hand, in females it is less common than cancer of the breast, cervix, ovary, thyroid and esophagus with a crude rate of 3.8 per 100,000 populations [1]. In addition, Sri Lanka also has one of the highest oral cancer mortality rates in the world.

\footnotetext{
* Correspondence: Tommaso.Lombardi@unige.ch

${ }^{2}$ Laboratory of Oral and Maxillofacial Pathology, Unit of Oral Medicine \& Division of Oral and Maxillofacial Surgery, Department of Surgery, University Hospitals of Geneva \& University of Geneva, 19, rue Barthelemy-Menn, 1205 Geneva, Switzerland

Full list of author information is available at the end of the article
}

Majority of the cancers that occur in the oral cavity are oral squamous cell carcinomas (OSCC) arising from the stratified squamous epithelial lining of the buccal mucosa, tongue, floor of the mouth, palate and lip. Tobacco use, either in the form of cigarettes, cigars, pipes and beedi or smokeless tobacco used for betel chewing has been without doubt shown to be the main culprit of OSCC $[2,3]$. Even with this knowledge, in Sri Lanka, OSCC is one of the major health problems as both males and females from rural areas of the country traditionally chew betel quid, which contains areca nut, tobacco, lime paste and spices wrapped in betel leaf [4]. In addition, betel chewing males also smoke and take alcohol, which further increases the susceptibility to develop OSCC.

The clinical outcome of patients with OSCC is assessed based on tumour-node-metastasis (TNM) system and at present it is the most reliable indicator on which 
therapeutic decisions are made. According to TNM staging, stage I or stage II disease defines a relatively small primary tumour with no nodal involvement. Stage III and stage IV includes large primary tumours, which may invade into underlying structures and/or spread to regional lymph nodes [5-7].

The main objective of this study was to describe selected clinico-pathological data for primary and recurrent OSCCs reported at the only University based Oral Pathology Diagnostic Service in Sri Lanka during a 2 years and nine month period, in order to highlight the magnitude of problem.

\section{Method}

Archives of the Department of Oral Pathology revealed a total of eight hundred and ninety six biopsies diagnosed as Oral squamous cell carcinomas during a two years and nine month period from 2009 to 2011 September. Out of the 896 biopsies, 801 were primary OSCCs, while 95 were recurrent OSCCs.

Data such as the patient's age, sex, site of the lesion and TNM staging were obtained from the biopsy request forms, while the histopathological diagnosis, status of the excision margins and lymph node involvement were obtained from the biopsy reports. Statistical analysis was performed using the Chisquare test.

Ethical clearance to analyze clinico-pathological information of the oral squamous cell carcinoma patients was obtained from the Dental Faculty, Ethics and review committee of the University of Peradeniya, Sri Lanka. The information was obtained retrospectively from biopsy request forms and oral pathology data base maintained in the department and the identity of each patient is not disclosed in the study. Therefore, according to the existing guidelines, it is not necessary to obtain written or verbal consent from each patient.

\section{Results}

The study sample comprised of $77 \%$ of Sinhalese, $19 \%$ of Tamil and $4 \%$ other ethnic groups. Approximately $68 \%$ of the patients lived in rural areas while only $32 \%$ were from urban and semi urban areas of the country. Table 1 shows the selected clinico-pathological characteristics of patients presenting with primary OSCC. Accordingly, the youngest patient presenting with OSCC was 20 years of age while the oldest patient was 93 years of age. In addition majority of the patients (78 \%) were in the $5^{\text {th }}$ to $7^{\text {th }}$ decades of life. Approximately $71.5 \%$ of the study sample comprised of males with a female to male ratio of 1:2.7. The buccal mucosa was the commonest site of primary OSCC comprising of $43 \%$ of the sample, followed by $23 \%$ with OSCC of the tongue. Twenty seven percent of the study sample had large
Table 1 Selected clinico-pathological characteristics of patients presenting with primary OSCC

\begin{tabular}{|c|c|}
\hline Feature & Number of patients (\%) $n=801$ \\
\hline \multicolumn{2}{|l|}{ Age } \\
\hline$<30-40$ & $28(03.5)$ \\
\hline $41-50$ & $132(16.5)$ \\
\hline $51-60$ & $257(32.1)$ \\
\hline $61-70$ & $219(27.3)$ \\
\hline$>70$ & $155(19.3)$ \\
\hline unknown & $10(01.3)$ \\
\hline \multicolumn{2}{|l|}{ Sex } \\
\hline Male & $573(71.5)$ \\
\hline Female & $212(26.5)$ \\
\hline unknown & $16(02.0)$ \\
\hline \multicolumn{2}{|l|}{ Site } \\
\hline Buccal mucosa & $349(43.6)$ \\
\hline Tongue & $190(23.7)$ \\
\hline Floor of the mouth & $66(08.2)$ \\
\hline Alveolar mucosa & $103(12.9)$ \\
\hline Palate & $73(09.1)$ \\
\hline Lip & $20(02.5)$ \\
\hline \multicolumn{2}{|l|}{ Number of sites involved } \\
\hline Single & $581(72.5)$ \\
\hline Two & $71(08.9)$ \\
\hline Three or more than three & $149(18.6)$ \\
\hline \multicolumn{2}{|l|}{ Clinical presentation } \\
\hline Ulcer & $408(50.9)$ \\
\hline White lesion & $57(07.1)$ \\
\hline Red/white mixed lesion & $33(04.1)$ \\
\hline Exophytic growth & $303(37.9)$ \\
\hline \multicolumn{2}{|l|}{ Type of Biopsy } \\
\hline Incision & $488(60.9)$ \\
\hline Excision & $313(39.1)$ \\
\hline \multicolumn{2}{|l|}{ Pathology } \\
\hline Early invasive SCC & $111(13.9)$ \\
\hline WDSCC & $360(44.9)$ \\
\hline MDSCC & $218(27.2)$ \\
\hline PDSCC & $37(04.6)$ \\
\hline Verrucous Carcinoma & $15(01.9)$ \\
\hline $\begin{array}{l}\text { Basaloid squamous cell } \\
\text { carcinoma }\end{array}$ & $27(03.4)$ \\
\hline Other & $33(04.1)$ \\
\hline
\end{tabular}

primary tumours, which involved two or multiple sites. With reference to clinical presentation, most primary OSCCs presented as ulcers or exophytic growths. Most primary OSCCs were sub classified as early invasive depending on the depth of tumour invasion and well, 
moderate or poorly differentiated OSCC depending on the degree of differentiation.

Table 2 also shows the type of surgical intervention, histopathological characteristics of excision margins and lymph node involvement of patients with primary OSCC who have undergone definitive surgical treatment with curative intent, when graded according to TNM stage. Although, majority of the patients (92\%) had received neck dissections, in addition to local excision, only $25 \%$ presented with lymph node metastasis. In addition, only $51 \%$ of the patients had completely excised primary tumours.

Table 3 shows some selected clinico-pathological characteristics of recurrent OSCC. Except for a single patient all the others who presented with recurrences were over 40 years of age. In addition, there were no statistically significant differences in the gender distribution, between the patients presenting with primary and recurrent OSCCs $(p>0.05)$. Majority $(46 \%)$ developed their recurrences within one year of the excision of the primary tumour while $27 \%$ had three years or more disease free period before the recurrence.

Table 4 shows a comparison of sex and site distribution of patients who are younger and older than 40 years. Accordingly, patients who were younger than 40 years tend to present with OSCC of the tongue $(P=0.00063)$ or floor of the mouth $(P=0.00031)$ more often compared to patients who were older than 40 years. However, no statistically significant changes were observed between the ratios of gender distribution in the two groups $(p<0.05)$.

When the relationship between the site of occurrence of the primary OSCC and presence or absence of lymph node metastasis was analyzed, (Table 5), primary
Table 3 Selected clinico-pathological characteristics of patients presenting with recurrent OSCC

\begin{tabular}{ll}
\hline Feature & Number of patients (\%) $n=95$ \\
\hline Age & $01(01.1)$ \\
$\quad<40$ years & $94(98.9)$ \\
$>41$ years & \\
Sex & $69(72.6)$ \\
$\quad$ Male & $26(27.4)$ \\
Female & \\
Site of Primary cancer & $42(44.2)$ \\
Buccal mucosa & $15(15.8)$ \\
Tongue & $38(40.0)$ \\
Other & \\
Tumour free period after treatment & $44(46.3)$ \\
$<1$ year & $24(25.3)$ \\
$1-2$ years & $11(11.6)$ \\
$3-4$ years & $16(16.8)$ \\
$>5$ years & \\
\hline
\end{tabular}

tumours which occurred on the tongue $(P=0.0029)$ and the floor of the mouth $(P=0.0026)$ showed a statistically significant higher tendency of developing lymph node metastasis compared to primary tumours of buccal mucosa. However, no significant differences were observed when lymph node metastasis rates were compared between tongue and floor of the mouth.

Primary tumours which extend to multiple sites do not seem to provide additional difficulty in obtaining complete clearance compared to tumours involving a single site (Table 6). However, neck nodes containing metastatic tumours is observed more often in patients

Table 2 Characteristics of the treatment received by the patients, and pathological findings

\begin{tabular}{|c|c|c|c|c|c|}
\hline Characteristics of treatment received by patients & TNM Stage 1 & TNM Stage 2 & TNM Stage 3 & TNM Stage 4 & Unknown \\
\hline Total number of patients at each TNM stage (\%) & $20(6.3)$ & $19(6.1)$ & $117(37.4)$ & $122(39.0)$ & $35(11.2)$ \\
\hline \multicolumn{6}{|l|}{ Type of surgery } \\
\hline Excision of the lesion only & 20 & 03 & -— & - & -— \\
\hline Excision of the lesion + Neck dissection & - & 16 & 117 & 122 & 35 \\
\hline \multicolumn{6}{|l|}{ *Status of the surgical margins of the lesion } \\
\hline Tumour with $>5 \mathrm{~mm}$ clearance & $14(70)$ & $15(79)$ & $71(60.6)$ & $50(41)$ & 12 \\
\hline Tumour with $<1 \mathrm{~mm}$ clearance & - & - & $24(20.5)$ & 46(37.8) & 09 \\
\hline Tumour with 1-5 mm clearance & $02(10)$ & - & 14(12.0) & 13(10.6) & - \\
\hline Tumour with dysplasia at excision margin/s & $04(20)$ & $04(21)$ & 08(06.9) & 13(10.6) & 14 \\
\hline \multicolumn{6}{|l|}{ Status of the lymph nodes } \\
\hline Metastasis present & - & $01(6.3)$ & $31(26.5)$ & $39(32)$ & 04 \\
\hline Metastasis absent & - - & 15(93.7) & $86(73.5)$ & $83(68)$ & 31 \\
\hline
\end{tabular}

Tumour with $>5 \mathrm{~mm}$ clearance at all excision margins are considered as completely excised

Tumour with $<1 \mathrm{~mm}$ clearance at one or more than one excision margin are considered as incompletely excised

Tumour with 1-5 mm clearance at one or more than one excision margin are considered as closely excised

Tumour with dysplasia at excision margins considered as such when any degree of dysplasia extends in to one or more than one excision margin 
Table 4 Comparison of sex and site distribution of patients presenting with primary OSCC who are younger and older than 40 years

\begin{tabular}{|c|c|c|c|}
\hline & $<40$ years $(\%)$ & $>40$ years $(\%)$ & Chi square test \\
\hline \multicolumn{4}{|l|}{ Sex } \\
\hline Male & $21(75.0)$ & $544(72.82)$ & NS $(P=0.79)$ \\
\hline Female & $07(25.0)$ & $203(27.18)$ & \\
\hline Total & 28 & 747 & \\
\hline \multicolumn{4}{|l|}{ Site } \\
\hline Buccal mucosa & $03(10.7)$ & $341(44.70)$ & Buccal mucosa vs tongue \\
\hline Tongue & $11(39.2)$ & $178(23.33)$ & $P=0.00063$ \\
\hline Floor of the mouth & 05 (17.8) & $61(07.99)$ & Buccal mucosa vs floor of the mouth \\
\hline Other & $09(32.3)$ & $183(23.98)$ & $P=0.00031$ \\
\hline Total & 28 & 763 & \\
\hline
\end{tabular}

who have large primary tumours which extend in to multiple sites compared to tumours which involve a single site only $(P=0.01)$ (Table 6$)$.

\section{Discussion}

Epidemiological studies have shown that betel quid chewing is a major risk factor for development of both oral and pharyngeal cancers and also oral pre-cancerous lesions $[2,4]$. Earlier reports in the 1980s from Sri Lanka and a recent report from Solomon Islands $[8,9]$ shows a very high rate of approximately $50 \%$ betel quid chewers in both sexes. However, a recent report from Sri Lanka [4] indicates a reduction in numbers of betel chewers, most probably the result of life style changes that have occurred over the years. In addition, a remarkable decline in the habit of smoking is also observed [10]. Accordingly, an article published by Ariyawardena et al. in 2011 [11], on oral and pharyngeal SCC incidence data over a period of 20 years obtained from hospital based cancer registry reports [1] has shown a decline. However, most experts in the field believe that under-reporting could have contributed to the above finding. Therefore, even at present Sri Lanka remains the country with the highest OSCC incidence in South East Asia [1, 12].

The Department of Oral Pathology, Faculty of Dental Sciences, University of Peradeniya, Sri Lanka is the only center in the entire country, which specializes in providing an Oral Pathology based, biopsy diagnostic reporting service. However, Pathologists with Medical degrees, also report on oral biopsies. Hence, the institution from which the present data is obtained does not report on all OSCCs detected in the country. In addition, a majority of the biopsies reported, come from the central province of Sri Lanka, where the institution is located.

Approximately, two thirds of the primary OSCCs reported from the Department of Oral Pathology was incisional biopsies, while only one third has been excisions. However, this does not reflect the true picture of the number of patients, who receive surgery with a curative intent, as some of the patients may have had excisions that have been reported by Pathologists attached to respective hospitals where the surgery was performed.

According to cancer incidence data for year 2005, compiled by the National cancer control programme, in Sri Lanka [1], male to female ratio of 3:1 have been observed. The male to female ratio of $2.7: 1$ observed in the present study is compatible with the above finding. In addition, according to the 2005 cancer incidence data [1], OSCC was shown to be more common in adults over 45 years, which is also compatible with our results. Furthermore, no discrepancies have been observed in the site distribution, with both studies reporting buccal mucosa and tongue as the commonest and $2^{\text {nd }}$ commonest sites where OSCCs occur. However, only $2.5 \%$ of the total primary SCCs has been diagnosed as lip cancers in the present study, which does not reflect the true

Table 5 The relationship between the site and presence/absence of lymph node metastasis

\begin{tabular}{llll}
\hline Primary site & Lymph node metastasis present $(n=75)(\%)$ & Lymph node metastasis absent $(n=215)(\%)$ & Chi square test \\
\hline Buccal mucosa (BM) & $21(16.0)$ & $109(84.0)$ & BM vs T ( $p=0.0029)$ \\
Tongue (T) & $20(37.7)$ & $33(62.3)$ & BM vs FOM ( $p=0.0026)$ \\
Floor of the mouth (FOM) & $12(46.2)$ & $14(53.8)$ & BM vs AM, P, L (NS) \\
Alveolar mucosa (AM) & $11(29.7)$ & $26(70.2)$ & FOM vs T (NS) \\
Palate (P) & $07(24.1)$ & $22(75.9)$ & \\
Lip (L) & $04(26.6)$ & $11(73.4)$ & \\
\hline
\end{tabular}


Table 6 The relationship between number of sites involved by the primary tumour and status of the excision margins and lymph node metastasis

\begin{tabular}{|c|c|c|c|c|}
\hline & Single site & Two sites & Multiple sites & Chi square test \\
\hline \multicolumn{5}{|l|}{ Status of excision margins } \\
\hline Tumour with $>5 \mathrm{~mm}$ clearance & 103(63.6) & $22(50.0)$ & $36(50.0)$ & \\
\hline Tumour with $<1 \mathrm{~mm}$ clearance & $45(27.8)$ & $12(27.3)$ & $22(30.5)$ & Single vs two sites $=$ NS \\
\hline Tumour with dysplasia at excision margin/s & $26(16.0)$ & 08(18.2) & $09(12.5)$ & Single vs two sites $=$ NS \\
\hline Tumour with $1-5 \mathrm{~mm}$ clearance & $22(13.4)$ & $02(4.5)$ & $05(7.0)$ & Two vs multiple $=$ NS \\
\hline \multicolumn{5}{|l|}{ Status of lymph nodes } \\
\hline \multirow[t]{2}{*}{ Lymph node metastasis present } & $41(21.1)$ & $10(30.3)$ & $24(38.0)$ & \\
\hline & & & & Single vs Multiple $p=0.01$ \\
\hline \multirow[t]{2}{*}{ Lymph node metastasis absent } & 153(78.9) & 23(69.7) & $39(62.0)$ & Single vs Two NS \\
\hline & & & & Two vs Multiple NS \\
\hline
\end{tabular}

incidence of lip cancers but only the number received by our institution. Because, although, majority of the intra oral SCCs are treated by Oral and Maxillo-facial Surgeons, cancer of the lip and parotid glands may receive surgical treatment from General Surgeons with Medical degrees, who would send their biopsies to Medical Pathologists.

Previous studies on epidemiological data of OSCCs from developed and developing countries have shown differences with respect to age, gender and site distribution $[13,14]$. These differences namely are as follows. In developed countries OSCCs are diagnosed more commonly in elderly patients in $7^{\text {th }}$ to $8^{\text {th }}$ decade of life while in developing countries it is more prevalent in patients in $5^{\text {th }}$ to $6^{\text {th }}$ decades of life. Generally males are more commonly affected compared to females by OSCC in both developed (male : female ratio 2.5: 1) and developing (male : female ratio 3:1) countries [1,13]. However, the difference between gender distributions is more in developing countries, when compared with developed countries. In developed countries the difference in the gender distribution is reducing in recent years due to more females taking up tobacco related habits including smoking [13]. With reference to site distribution, although the tongue is considered as the commonest site of occurrence of primary OSCCs in developed countries, betel chewing results in cancer of the buccal mucosa more commonly in patients from developing countries. This is mainly because constituents of betel quid which is claimed to produce a sense of well being and increased capacity to work by stimulation of parasympathetic nervous sysem is kept in the buccal pouch for prolonged periods of time in order to obtain maximum effect [14].

Majority of the primary tumours comprised of conventional OSCCs, out of which $13 \%$ were early invasive SCCs. The advantage of having an early invasive OSCC, includes, ability to obtain complete clearance without mutilative extensive surgery, which results in having a higher chance of achieving a complete cure. In addition, more aggressive poorly differentiated OSCCs, were very few in number comprising only $4 \%$ of the total sample, most probably reflecting the contribution of etiological factors such as betel chewing towards the development of well or moderately differentiated tumours. The verrucous carcinomas have the best prognosis $[15,16]$, due to absence of invasion and metastasis also comprised of only $1 \%$ of the study sample. These tumours usually occur with the use of beedi, a specific form of tobacco smoking practiced in South Asia [8]. The very low incidence of verrucous carcinoma cannot be attributed to a reduction in the risk habit as there is no decrease in the consumption of beedi reported in recent years [10]. Therefore, the fact that verrucous carcinomas that do not receive surgical treatment tends to develop in to SCCs $[15,16]$ may have contributed to the very low incidence identified in the present study.

In our study sample (Table 2) majority of the patients who received surgical excision of the primary tumour also received neck dissections. Some received prohylatic neck dissections while remaining neck dissections were performed with therapeutic intention. Types of neck dissections that the patients had received included radical and modified radical neck dissections [17]. In the present sample, out of the different types mentioned above most patients had received different types of selective neck dissections. The fact that majority of patients received neck dissections and the fact that approximately $45 \%$ of the tumours were incompletely or closely excised or had dysplasia in excision margins support the fact that most patient being late presenters with large (T3/4) primary tumours. In addition, the fact that majority of our Oral and Maxillofacial Surgeons operate without the availability of frozen sections may have also contributed to the relatively large percentage of patients who ended up with incompletely excised primary tumours. 
No difference in gender or site distribution was observed between primary and recurrent OSCCs in the present study sample. The most interesting finding with reference to recurrent OSCCs was the fact that majority of the tumours occurred within two years of the first surgery. In addition, all the recurrent OSCCs developed in patients with completely excised primary tumours. As there would have been at least changes that could be detected at molecular level in these patients without which the chance of developing a recurrence is very remote, investigations to identify these molecular changes would be extremely useful to prevent recurrences in the future.

The fact that younger patients develop OSCCs on the tongue and FOM in contrast to buccal mucosa suggests that some known (smoking/alcohol) and unknown aetiological factors other than betel quid chewing may play a major role in these patients [8]. The role played by these hitherto unknown factors needs further investigations.

\section{Conclusion}

In conclusion, this study confirms previously established demographic factors such as age, gender and site distribution for OSCCs in Sri Lankan patients. In addition, the study highlights the importance of initiating more preventive and early detection strategies, due to the fact that most primary tumours at present require extensive surgery, which carries a high mortality and morbidity rate.

\section{Abbreviations}

OSCC: oral squamous cell carcinoma; TNM: tumour-node-metastasis staging; FOM: floor of the mouth.

\section{Competing interests}

The authors declare that they have no competing interests.

\section{Authors' contributions}

1. PRJ was involved in the study design, literature review, data analysis and manuscript preparation. 2. TNP carried out the data collection. 3. BRRNM was involved in the development of the concept and was responsible for the critical review of the manuscript. 4. TL was involved in the development of the concept and was responsible for the critical review of the manuscript. All authors read and approved the final manuscript.

\section{Acknowledgements}

Authors are grateful to all Oral Pathologists, Technical staff and clerical staff of the department of Oral Pathology for their contribution in making information easily accessible. All Oro-Maxillofacial Surgeons are acknowledged for sharing the clinical information of their respective patients.

\section{Author details}

'Department of Oral Pathology, Faculty of Dental Sciences, University of Peradeniya, Peradeniya, Sri Lanka. ${ }^{2}$ Laboratory of Oral and Maxillofacial Pathology, Unit of Oral Medicine \& Division of Oral and Maxillofacial Surgery, Department of Surgery, University Hospitals of Geneva \& University of Geneva, 19, rue Barthelemy-Menn, 1205 Geneva, Switzerland.

Received: 30 January 2015 Accepted: 18 November 2015 Published online: 08 January 2016

\section{References}

1. Cancer incidence data Sri Lanka, year 2001-2005 available at www.nsf.ac.lk newsletter/NOL1NO6/cancer.pdf
2. Llewellyn $C D$, Johnson NW, Warnakulasuriya KAAS. Risk factors for squamous cell carcinoma of the oral cavity in young people-a comprehensive literature review. Oral Oncol. 2001;37:401-18.

3. Daftary DK, Murti PR, Bhonsle RB, Gupta PC, Mehta FS, Pindborg JJ. Risk factors and risk markers for oral cancer in high risk areas of the world. In: Johnson NW, editor. Oral cancer: detection of patients and lesions at risk. Cambridge: Cambridge University Press; 1991. p. 29-63.

4. de Silva VA, Hanwella DRC, Gunawardena N. Prevalence of betel chewing among males in Colombo and Polonnaruwa districts. J Coll Commun Physicians Sri Lanka. 2009;14:20-3.

5. Lydiatt DD, Robbins KT, Byers RM, Wolf PF. Treatment of stage I and II oral tongue cancer. Head Neck. 1993;15:308-12.

6. Layland MK, Sessions DG, Lenox J. The influence of lymph node metastasis in the treatment of squamous cell carcinoma of the oral cavity, oropharynx, lanynx, and hypopharynx: N0 versus N+ neck. Laryngoscope. 2005:115:629-39.

7. Iype EM, Sebastian P, Mathew A, Balagopal PG, Varghese BT, Thomas S. The role of selective neck dissection (I-III) in the treatment of node negative (N0) neck in oral cancer. Oral Oncol. 2008;44:1134-8.

8. Warnakulasuriya KAAS. Smoking and chewing habits in Sri Lanka: implications for oral cancer and precancer. Gupta PC, Hamner JE, Murti PR eds. Control of tobacco related cancers and other diseases. International symposium 1990, Bombay. Oxford University press, 113-118.

9. Tovosia S, Chen PH, Ko AM, Tu H, Tsai P, Ko YC. Prevalence and associated factors of betel quid use in the Solomon Islands: a hyperendemic area for oral and pharyngeal cancers. Am J Trop Med Hyg. 2007;77:586-90.

10. Alcohol and drug information center. Tobacco profile. Colombo, Sri Lanka: ADIC; 2007.

11. Ariyawardena A, Warnakulasuriya S. Declining oral cancer rates in Sri Lanka: are we winning the war after being at the top of the cancer league table? Oral Dis. 2011;17:636-41.

12. Warnakulasooriya KAAS. Cancer in Sri Lanka with special reference to oral cancer. In: Wada T, Akoi K, Tachi A, editors. Current status in cancer research in Asia, Middle East and other countries. Nagoya: The Nagoya University Press; 1987. p. 237-44.

13. Silverman S. Demographics and occurrence of oral and pharyngeal cancers. The outcomes, the trends and the challenge. JADA. 2001;132:7-10.

14. Madani AH, Dikshit M, Bhaduri D, Jahromi AS, Aghamolaei T. Relationship between selected socio-demographic factors and cancer of oral cavity - a case control study. Cancer Inform. 2010;9:163-8.

15. Slootweg PJ, Merkx TAW. Premalignant lesions of the oral cavity. In: Barnes L, editor. Surgical pathology of the head and neck. 3rd ed. New York: Informa Healthcare; 2008. p. 267-84.

16. El-Mofty SK, Lewis JS. Cancer of the oral cavity and oropharynx. In: Barnes L, editor. Surgical pathology of the head and neck. 3rd ed. New York: Informa Healthcare; 2008. p. 285-343

17. Robbins KT, Clayman G, Levine PA, Medina J, Sessions R, Shaha A, et al. Neck dissection classification update: revisions proposed by the American Head and Neck Society and American Academy of Otolaryngology - Head and Neck Surgery. Arch Otolaryngol Head Neck Surg. 2002;128:751-8.

Submit your next manuscript to BioMed Central and we will help you at every step:

- We accept pre-submission inquiries

- Our selector tool helps you to find the most relevant journal

- We provide round the clock customer support

- Convenient online submission

- Thorough peer review

- Inclusion in PubMed and all major indexing services

- Maximum visibility for your research

Submit your manuscript at www.biomedcentral.com/submit
) Biomed Central 